\title{
A Proposed Framework for Developing User-Centred Mobile Healthcare Applications for the Biggest Annual Mass Gathering (Hajj) Post COVID-19
}

\author{
Nowman Islam \\ School of \\ Computing and Engineering \\ University of West London \\ St. Mary's Road, Ealing, UK \\ 21339907@student.uwl.ac.uk
}

\author{
Aamir Anwar \\ School of \\ Computing \& Engineering \\ University of West London \\ St. Mary's Road, Ealing, UK \\ 21452391@student.uwl.ac.uk
}

\author{
Ikram Rehman \\ School of \\ Computing \& Engineering \\ University of West London \\ St. Mary's Road, Ealing, UK \\ Ikram.Rehman@uwl.ac.uk
}

\begin{abstract}
The Hajj pilgrimage being the largest annual mass gathering globally with two to three million participants from over 180 counties, will remain a high priority for diseases surveillance for future epidemics or any other international public health emergencies with rapid scalability. This paper highlights the importance of monitoring mass gatherings during a pandemic and how mHealth applications can reduce the burden on health facilities during a mass gathering and tackle future infectious diseases outbreaks. The paper also highlights the importance of developing a user-centred application when designing for a diverse group of users with a shared purpose. As a result, a framework has been proposed to update the current applications or design and develop future mobile health applications. The framework has been developed based on the rationale and evidence found in the literature.
\end{abstract}

Keywords - Covid-19, Mass Gathering, Hajj, mHealth (Mobile Healthcare), Persuasive System Design (PSD), Sentiment Analysis, User-Centred Design (UCD), Double Diamond.

\section{INTRODUCTION}

According to the World Health Organisation (WHO) a "mass gathering" is any gathering of people in a location where the health systems and facilities are pushed and strained to their boundaries or more [1].

There are currently over 1.8 billion Muslims worldwide, making "Islam" the second-largest and fastest-growing religion globally, as reported by Pew Research Centre [2]. Hajj is one of the five pillars of Islam, and it consists of visiting the holy city of Mecca, which is located in the Kingdom of Saudi Arabia (KSA). In an editorial article on the Bulleting, WHO stated that the Hajj pilgrimage is the largest annual mass gathering in the world, with 2 to 3 million adult Muslim participants from over 180 countries in the KSA [3].

In January 2020, WHO announced a Public Health Emergency of International Concern (PHEIC), identifying the Covid-19 as a worldwide pandemic. It is not the first time that a deadly virus has speeded around the world. We have previously seen SARS (Severe acute respiratory syndrome) and MERS (Middle East respiratory syndrome). However, this is the first time that a virus had a global effect [4]. A covid-19 mortality analysis by Johns Hopkins
University \& Medicine shows that nearly every county on the planet has been affected by the deadly virus [5].

This pandemic means that not only are the personal lives affected by the disease but entire economies and nations are also affected, including $\mathrm{KSA}$, where the biggest annual mass gathering takes place. As a result, one of the most critical questions that had significant attention in the Muslim world is whether the KSA authorities would allow the Hajj to take place on a full scale, reduce scale, or temporarily discontinue the entire pilgrimage, which originated in 2000 B.C. [6].

Due to the rapid community transmission of the deadly virus, the authorities responded to the dire state by scaling down the Hajj pilgrimage to only 1000 participants residing in the Kingdom compared to the 2.5 million participants in the previous year [7].

Digital technologies advancement in the health sector, including Big data and artificial intelligence (AI), have supported and facilitated many countries around the globe to stop the spread of the deadly Covid-19 infections [8]. In a digital health laws and regulations of Saudi Arabia report of 2021 [9], a range of mobile health applications for the KSA is 
recommended. These applications are developed by leading authorities such as the Ministry of Health.

It is uncertain if the KSA authorities' current mobile healthcare systems are ready to support the existing healthcare facilities of the Hajj pilgrimage for a post-Covid-19 scenario with a full-scale pilgrimage. This is important because participants are from over 180 counties with different socioeconomic backgrounds, technology capabilities and language barriers.

The main contribution of this paper is a proposal of a framework to the Saudi Ministry of Health $(\mathrm{MOH})$ for designing and developing future Mobile health applications or updating the current applications to be more human-centred with an increased user experience level and adoption rate based on the evidence gathered from the literature dating from 2012 to mostly 2021 on topic such as "Mass gathering health threats", "Hajj health issues", "Mobile Apps during Hajj", "Saudi mHealth apps","User review analysis", "persuasive mHealth" and "Design Thinking in mHealth".

\section{RELATED WORK}

\subsection{Types of Mass Gatherings and their health threats}

In a systematic review of public health threats in mass gatherings published by Cambridge University Press in June 2019 [10], it has been mentioned that there are mainly three types of mass gatherings (MGs) taking place around the globe and they are: 1) religious MGs, 2) festival MGs and 3) sporting MGs. The review aimed to identify and assess the health threats associated with each type of the MGs mentioned above. The study was performed on 45 articles out of 1264 references found through the Web of Science, Medline, and Scopus database. The main findings of the review are as follows:

1. In the festival-related mass gatherings, the most common health risk were alcohol and drugs-related issues.

2. In the sporting type of mass gatherings, the most common health risk identified is injuries. Alcohol, drugs, and infectious diseases are other risks identified.

3. In the religious type of mass gathering, the most common health problem identified was infectious diseases. In addition, environment and road traffic-related risks were also found.

The review concluded by recommending that the organisers of the mass gatherings assess the type of the MGs and the health and safety needs of the participants with the proper planning for the healthcare facilities critically.

All the findings by the authors are confirmed in a report by WHO published in 2015 titled "Public Health for Mass Gathering: Key Considerations [11]. The report aims to provide advice, recommending methods and frameworks to mass gathering organisers on prevention, detection and management of public health incidents [10].

\subsection{Health issues and current health system during the Hajj Pilgrimage}

A research study has reviewed 60 articles on health issues during the hajj pilgrimage from 20052014 [12]. The authors primarily retrieved 335 research papers from PubMed, a leading and trusted biomedical and life sciences literature database. The paper's goal was to provide recommendations on the policies to prevent the pilgrims' health risks. The paper's outcome resulted in three categories using only qualitative analysis: health services, communicable disease, and noncommunicable disease. The authors reported that respiratory-related diseases are most common during the pilgrimage. There is a low satisfaction rate on the physicians' services, and that special attention is needed to improve the hajj participants' experience. It is also reported that more evaluation studies are required with Saudi's health services during the Hajj period to make recommendations for improvements. The paper concluded by stating that the optimal utilisation of the current Hajj health system's collected data is yet to be achieved [12].

\section{3 mHealth apps by the KSA authorities during Covid-19}

A recent research paper published in 2020, "Digital response during the covid-19 pandemic in Saudi Arabia", highlighted that the KSA authorities partnered with the private sector companies to develop and launch approximately 19 platform/applications to support the public healthcare services during the Covid-19 pandemic. The authors did not mention if these applications are an excellent fit to serve the largest annual mass gathering hosted in the Kingdom for a post-Covid19 scenario. On the contrary, the authors recommended reducing the number of mHealth apps by merging the various features [13].

Another paper also published during Covid-19 in 2020 [13] evaluated the mHealth applications developed by the Ministry of Health (MOH) for public use. The study aimed at identifying and understanding the design of two applications in particular by evaluating their persuasive features. Both the applications included in the study were developed by the MOH. The first is called "Sehha", 
a telemedicine application where users can remotely consult via text, voice message, images and videos with qualified doctors approved by $\mathrm{MOH}$. The second app is called "Mawid", which enables patients to book their appointments, cancel or reschedule with health centres and hospitals. The author recommended improving the design and including persuasive features in the application published by $\mathrm{MOH}$.

The lack of understanding of the human context by the app developers and other stakeholders can result in developing and launching products that will remain primarily unused and not meeting the project objectives. The design thinking principles is a robust methodology that can close the gap by involving the user needs and feedback throughout the development of new healthcare systems, especially mobile healthcare applications [14].

As mHealth applications are becoming a popular way to motivate users toward healthy behaviour, the design and inclusion of the functionalities play a significant role in persuading the public to use those apps. Therefore, the impact of mHealth apps is dependent on their adaptability to be acceptable to various users [13].

An industry report titled "mHealth 2030" by ORCHA, the world's leading health app evaluation and advisor organisation [15], discussed that users would be the principal stakeholder for the failure of success of the mHealth ventures. In the same report, an expert comment explains that there are and will be a surplus number of mHealth apps for the users to choose from, and not all of them are developed to keep the user's interest. Therefore, only the applications that meet the user need will succeed in the longer run by carefully identifying and including the unique selling points (USP), making regular updates and most importantly, integrating persuasive design as we see in the gaming industry [15].

\section{PROPOSED FRAMEWORK}

Our proposed framework to design, develop new mHealth applications for the Hajj pilgrimage consists of using sentiment analysis for detecting the user experience state on the current apps developed by KSA and the Persuasive System Design (PSD) framework within the British Design Council's Double Dimond methodology to influence, reinforce or change health-related behaviours or attitudes of users during the Hajj pilgrimage.
Islam et al.

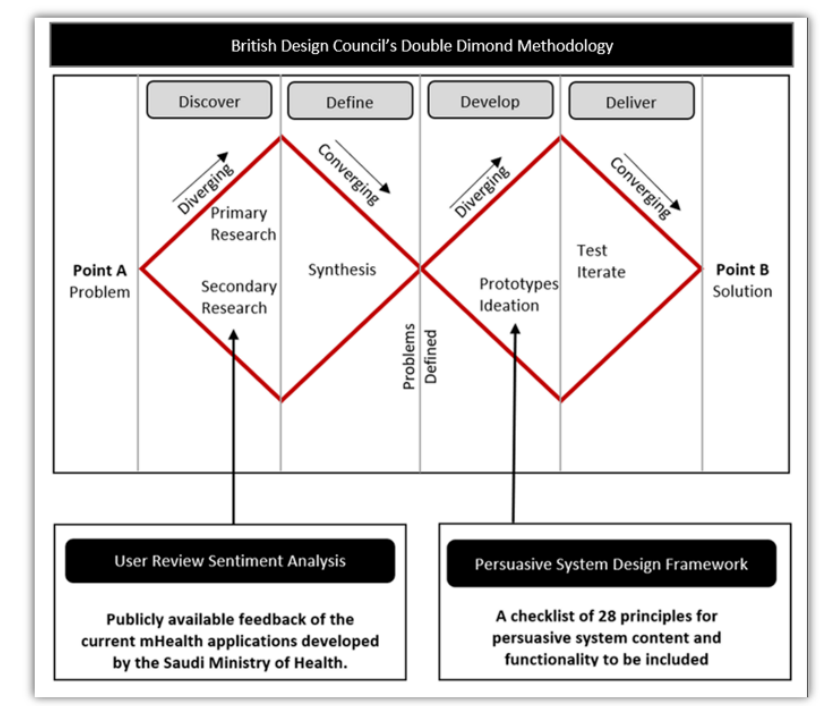

Figure 1: Proposed Framework

\subsection{British Design Council's Double Dimond}

The Double Dimond method works in a way that both designers and non-designers can understand the processes. They represent a process of exploring the problems with a broad view called "diverging thinking" and then taking focused actions called "convergent thinking" [16]. The reason for selecting this methodology in the framework is the fundamental characteristic of its human-centred approach. This is a collaborative way between designers and other stakeholders such as users in a co-creation or co-participatory setting, shifting the attitude from designing "for users," which is the traditional app development process, to a humancentred approach of designing "with users"[14].

There are mainly four phases in this methodology:

1. Discover: In this phase, designers need to address the problem and understand them clearly. In the context of the Hajj, a question could be "how do I design and develop an app that tracks pilgrims, preventive measures and monitors diseases for users with different socio-economic backgrounds, languages and technology capabilities". Authorities should recruit diverse teams of experienced pilgrims from various countries when carrying primary research through surveys, observations, and user diaries. This is because experienced pilgrims know the Hajj rituals at best, and they are also familiar with the locations and the health implications. In the secondary research, the authorities should extensively study the Hajj statistics yearbook, where a detailed breakdown of the pilgrims' demographics is given. Other relevant secondary research can be carried out once the participants' countries are identified.

2. Define: This phase is where all the unstructured research findings get refined through 
N. Islam et al.

in-depth research tools such as focus groups and user journey mappings.

3. Develop: This phase is where ideas are brainstormed on clearly defined problems from the previous phase. It is suggested to seek inspiration from successful mHealth applications from other countries and co-design with the recruited people from the earlier phases.

4. Deliver: This phase is where small scale solutions are developed and tested out with a set of users for collecting essential data such as user acceptance rate etc. This stage is highly iterative, so it is not a linear process.

\subsection{User Reviews Sentiment Analysis}

Sentiment Analysis (SA) is a data mining technique used to analyse social media, political campaign, or product reviews data, to name just a few. This is a key indicator of user satisfaction and user experience [17]. SA is a process that uses artificial intelligence $(\mathrm{Al})$ to assign a negative $(-1)$ value or a positive value $(+1)$ to a piece of text. An example would be "the app is well designed, but it keeps crashing". SA has the potential to analyse and filter out subjective opinions of users from an app review section. The most crucial benefit of this technology is the ability to find out the user sentiments through subjective words such as "awesome", "great", "lifesaver", "useless", "crushing", "confusing", "pointless", and so on. [18].

We propose to embed SA in the double diamond's discovery phase along with other designer tools where the design team performs primary and secondary research. Therefore, analysing the publicly available user reviews of the existing apps developed by the KSA can give valuable insights into the current state of the user experience.

\subsection{Persuasive Systems Design Framework (PSD)}

The PSD is a framework developed to design and evaluate persuasive systems [19]. For an application to be persuasive, it is vital to analyse the use context of the system. In this case, it is the Hajj pilgrimage. It is also essential to understand the role of the persuader (Ministry of Health) and persuadee (Hajj participants), their communication channel, and what content is being communicated. Moreover, the design and the innovation team should analyse users' needs, motivations, technical abilities, personalities, and interest, among many other factors [19].

The PSD framework consists of a checklist of 28 design principles in four categories based on activities a user is set to accomplish, as shown in Table 1
Table 1: PSD Design Principles Checklist [19].

\begin{tabular}{|l|l|l|l|}
\hline \multicolumn{1}{|c|}{$\begin{array}{c}\text { Primary Task } \\
\text { Support }\end{array}$} & $\begin{array}{c}\text { Dialogue } \\
\text { Support }\end{array}$ & \multicolumn{1}{|c|}{$\begin{array}{c}\text { Social } \\
\text { Support }\end{array}$} & $\begin{array}{l}\text { System } \\
\text { Credibility } \\
\text { Support }\end{array}$ \\
\hline Reduction & Praise & $\begin{array}{l}\text { Social } \\
\text { learning }\end{array}$ & $\begin{array}{l}\text { Trustworthin } \\
\text { ess }\end{array}$ \\
\hline Tunnelling & Rewards & $\begin{array}{l}\text { Social } \\
\text { comparison }\end{array}$ & Expertise \\
\hline Tailoring & Reminders & $\begin{array}{l}\text { Normative } \\
\text { influence }\end{array}$ & $\begin{array}{l}\text { Surface } \\
\text { credibility }\end{array}$ \\
\hline Personalization & Suggestion & $\begin{array}{l}\text { Social } \\
\text { facilitation }\end{array}$ & $\begin{array}{l}\text { Real-world } \\
\text { feel }\end{array}$ \\
\hline Self-monitoring & Similarity & Cooperation & Authority \\
\hline Simulation & Liking & Competition & $\begin{array}{l}\text { Third-party } \\
\text { endorsement }\end{array}$ \\
\hline Rehearsal & Social role & Recognition & Verifiability \\
\hline
\end{tabular}

As discussed in the related work section, WHO highly endorses the human-centred approach when designing mobile healthcare applications [20].

In Figure 2. we can see that the Persuasive System Design has been embedded within the British council's double diamond's third phase (develop). As illustrated in Table 1, the inclusion of any relevant principles will be beneficial when brainstorming ideas for prototyping mHealth applications [21]. As an example, a Minimum Viable Product (MVP) would adhere the trustworthiness, and authority principles from the Table 1 . by including truthful information by authoritative figures such as Ministry of Health or WHO.

\section{CONCLUSION}

This paper presents the preliminary findings from the literature on the importance of mass gatherings during a pandemic and how mHealth applications help the health facilities in mass gatherings. We also discussed the importance of developing a usercentred application when designing for a diverse group of users with a shared purpose. Findings included the endorsement of a user-centred approach for mHealth application from the WHO and research papers in prestigious journals. This paper proposed a new theoretical framework for the KSA authorities to facilitate the design and development of future mHealth applications. The framework has the potential to improve the user acceptance rate and engagement level, which currently lacks in mHealth apps in the context of the Hajj pilgrimage.

\section{REFERENCES}

[1] "Coronavirus disease (COVID-19): Mass gatherings." https://www.who.int/newsroom/q-a-detail/coronavirus-disease-covid- 
19-mass-gatherings (accessed Apr. 23,

N. Islam et al. 2021).

[2] "Muslims and Islam: Key findings in the U.S. and around the world | Pew Research Center." https://www.pewresearch.org/facttank/2017/08/09/muslims-and-islam-keyfindings-in-the-u-s-and-around-the-world/ (accessed Apr. 28, 2021).

[3] Z. A. Memish and A. A. Al-Rabeeah, "Public health management of mass gatherings: The saudi arabian experience with MERSCoV," Bulletin of the World Health Organization, vol. 91, no. 12. World Health Organization, p. 899, 2013, doi: 10.2471/BLT.13.132266.

[4] N. N. Chathappady House, S. Palissery, and $\mathrm{H}$. Sebastian, "Corona Viruses: A Review on SARS, MERS and COVID-19," Microbiol. Insights, vol. 14, p. 117863612110024, Jan. 2021, doi: 10.1177/11786361211002481.

[5] "Mortality Analyses - Johns Hopkins Coronavirus Resource Center." https://coronavirus.jhu.edu/data/mortality (accessed Apr. 29, 2021).

[6] "A Brief History Of the Hajj - TIME." http://content.time.com/time/world/article/0,8 599,1864624,00.html (accessed Apr. 28, 2021).

[7] "Hajj 2020: What you need to know about this year's pilgrimage | Coronavirus pandemic News | Al Jazeera." https://www.aljazeera.com/news/2020/7/25/ hajj-2020-what-you-need-to-know-aboutthis-years-pilgrimage (accessed Apr. 29, 2021).

[8] S. Whitelaw, M. A. Mamas, E. Topol, and H. G. C. Van Spall, "Applications of digital technology in COVID-19 pandemic planning and response," The Lancet Digital Health, vol. 2, no. 8. Elsevier Ltd, pp. e435-e440, Aug. 01, 2020, doi: 10.1016/S25897500(20)30142-4.

[9] "Digital Health 2021 | Saudi Arabia | ICLG." https://iclg.com/practice-areas/digital-healthlaws-and-regulations/saudi-arabia (accessed May 07, 2021).

[10] M. Karami et al., "Public Health Threats in Mass Gatherings: A Systematic Review," Disaster Medicine and Public Health Preparedness, vol. 13, no. 5-6. Cambridge University Press, pp. 1035-1046, Dec. 01, 2019, doi: 10.1017/dmp.2018.161.

[11] "WHO | Public Health for Mass Gatherings: Key Considerations," World Health
Organization, 2015. Accessed: May 06, 2021. [Online]. Available:

http://www.who.int/ihr/publications/WHO_H SE_GCR_2015.5/en/.

[12] M. R. Aldossari, A. Aljoudi, and D. Celentano, "Health issues in the hajj pilgrimage: A literature review," Eastern Mediterranean Health Journal, vol. 25, no. 10. World Health Organization, pp. 744753, Oct. 01, 2019, doi: 10.26719/2019.25.10.744.

[13] A. Shati, "Mhealth Applications Developed by the Ministry of Health for Public Users in KSA: A Persuasive Systems Design Evaluation," Heal. Informatics - An Int. J., vol. 9, no. 1, pp. 1-13, 2020, doi: 10.5121/hiij.2020.9101.

[14] K. Tschimmel, "Design Thinking as an effective Toolkit," Action Innov. Innov. from Exp. Barcelona, pp. 1-20, 2012.

[15] "mHealth 2030 Report - ORCHA." https://orchahealth.com/mhealth-2030report/ (accessed Jun. 01, 2021).

[16] "What is the framework for innovation? Design Council's evolved Double Diamond | Design Council."

https://www.designcouncil.org.uk/newsopinion/what-framework-innovation-designcouncils-evolved-double-diamond (accessed May 09, 2021).

[17] "Sentiment Analysis turns Customer Reviews into Insights - Vendasta Blog." https://www.vendasta.com/blog/sentimentanalysis-turns-reviews-into-insights/ (accessed May 09, 2021).

[18] M. Hassounah, H. Raheel, and M. Alhefzi, "Digital response during the COVID-19 pandemic in Saudi Arabia," Journal of Medical Internet Research, vol. 22, no. 9. JMIR Publications Inc., p. e19338, Sep. 01, 2020, doi: 10.2196/19338.

[19] I. Adaji and J. Vassileva, "Evaluating Persuasive Systems Using the PSD Framework," undefined, 2016.

[20] WHO Global Observatory for eHealth., MHealth : new horizons for health through mobile technologies. Switzerland: World Health Organization, 2011.

[21] H. Oinas-Kukkonen and M. Harjumaa, "Persuasive Systems Design: Key Issues, Process Model, and System Features," Commun. Assoc. Inf. Syst., vol. 24, pp. 485-500, 2009, doi: 10.17705/1CAIS.02428. 